\title{
Fetal nuchal translucency thickness in different cut-off points for aneuploidy screening in the south of Vietnam
}

\author{
Xuan-Hong Tomai ${ }^{1}$, Jean-Pierre Schaaps ${ }^{2}$ and Jean-Michel Foidart ${ }^{2}$ \\ ${ }^{I}$ Department of Obstetrics and Gynaecology, University of Medicine and Pharmacy, Ho Chi Minh City, Vietnam; and ${ }^{2}$ Department of \\ Obstetrics and Gynaecology, University of Liège, Liège, Belgium
}

\begin{abstract}
Aims: The purpose of this study was to define the most suitable cut-off point for fetal nuchal translucency thickness in a screening program for aneuploidy and trisomy 21 in the south of Vietnam. Material \& Methods: Two thousand and five hundred cases of singleton pregnancies were followed prospectively from the first trimester to the delivery. The rate of aneuploidy was calculated by seeking a relationship to increased fetal nuchal translucency thickness then calculating the sensitivity and specificity of different cut-off points in thickness measurement to find the most suitable point for screening.

Results: The prevalence of fetal abnormality was $1.5 \%$ (95\% CI 1.1-2.1), and $1.2 \%$ (95\% CI $0.8-1.7$ ) of aneuploidy cases found and the commonest was trisomy 21 . A cut-off point at $2.4 \mathrm{~mm}$ showed the highest level of sensitivity and specificity for the detection of aneuploidy (65.5 and 95.7\%) and trisomy $21(75.0$ and 95.1\%), with a false-positive rate of 4.3 and $4.9 \%$, respectively.
\end{abstract}

Conclusion: Using a cut-off point of nuchal translucency at $2.4 \mathrm{~mm}$ has potential for aneuploidy and trisomy 21 screening in the south of Vietnam.

Keywords: aneuploidy, cut-off point, fetal nuchal translucency thickness, first trimester, trisomy 21.

\section{INTRODUCTION}

In screening for trisomy 21 and other chromosomal abnormalities, measurement of nuchal translucency (NT) thickness in the first trimester between 45 to $84 \mathrm{~mm}$ of crown-rump length (CRL) (11.2 to 13.6 weeks of gestation), combined with maternal age and serum biochemistry, can be an effective method. ${ }^{1-5}$ The detection rate of these fetal chromosomal defects varied from 75 to $91 \%$ with a $1.0-5.4 \%$ false-positive rate when using the strategy of this combined test, this being shown in many countries. ${ }^{6-9}$ According to Brady et al., when fetal NT level increases the chance that a healthy baby will be born decreases. ${ }^{10}$ It is quite important to define the presence of an increased fetal NT thickness in the first trimester of gestation, because the fetal NT thickness increases as CRL increases. ${ }^{2,6}$ Therefore, many authors have proposed taking gestational age into account when determining whether a given NT thickness is considered as increased. ${ }^{10-12}$

Many studies have asserted different cut-offs of NT for screening chromosomal aberration: some studies used a fixed cut-off of $3.0 \mathrm{~mm}$ with $75 \%$ of detection rate for trisomy 21 screening;, ${ }^{2,13}$ others considered a NT at 2.5 $\mathrm{mm}$ as a positive screening values with a $14.8 \%$ of positive predictive value $;^{14,15}$ and recently, the use of the 95 th percentile of NT thickness according to CRL (P95 CRL) showed a higher sensitivity for detecting chromosomal aberrations than using fixed cut-off point $(3.0 \mathrm{~mm})(70.9 \%$ of sensitivity with a $5.8 \%$ false-positive rate using a 95th percentile method versus $54.8 \%$ sensitivity with a $3.5 \%$ false-positive rate using a fixed cut-off). ${ }^{16,17}$ The choice of fetal NT cut-off point depends on the strategy of prenatal screening and on the risk of the obstetrical population in each country.

In this context, we carried out a prospective study to evaluate the distribution of fetal NT thickness and to define the most suitable cut-off point of fetal NT thickness for the predicting of the occurrence of aneuploidy and trisomy 21 in the prenatal diagnostic program in the south of Vietnam.

\section{METHODS}

\section{Study population}

Between 1 January and 31 December 2009, all singleton pregnant women were offered fetal NT measurement and serum biochemistry in the first trimester (with CRL measurement from 45 to $84 \mathrm{~mm}$ ) as part of routine prenatal care. The multi-pregnancies and nonviable fetuses were excluded from the study. The gestational age was calculated in weeks and days based on the results of CRL measurement in millimeters. Women also underwent a fetal morphological scanning routinely in the second trimester (18-24 weeks) for screening 
structural malformation.

\section{Clinical testing}

The measurement of fetal NT was performed by sonographers trained and certified for measurement of fetal NT by the Fetal Medicine Foundation (FMF), UK guidelines. These sonographers had at least 5 years experience for ultrasound scan of fetal morphology. All pregnancies were carried out by using a transabdominal probe. Fetal NT was measured according to criteria of FMF: CRL was in range from 45 to $84 \mathrm{~mm}$; fetus in sagittal position with spine situated posteriorly; fetus in neutral position with no hyperextension or flexion; NT clearly visible for measurement; and at least three fetal NT measurements were taken and the largest of the three measurements was recorded. ${ }^{18}$ An anatomic survey was done following a standardized protocol at the time of the fetal NT scan.

All measurements were performed transabdominally by using SONOACE 8800 (MEDISON, Seoul, South Korea) and VOLUSON 730 PRO (GE, New York, NY, USA). The curved array (C7-3 or C5-2) transducer was equipped for fetal NT measurement in the first trimester and the 3D4-7EK transducer for fetal structural examination in the second trimester of gestation.

\section{Laboratory test}

For biochemistry test, the serum was separated and analyzed for free beta subunit of human chorionic gonadotropin and pregnancy-associated plasma protein-A using Immulite DPC (Diagnostic Products Cooperation) 2000 from Typolog Software Limited and Company KG (Tomesch, Germany). Based on maternal age, fetal NT thickness and serum markers, the risk of fetal chromosomal malformation (trisomy 21, trisomy 18) was calculated as combined test, following the results of Prisca software in Immulite DPC 2000 machine. A combined test was defined as positive at the threshold of 1 in 250 or more according to recommendation of Wald et al., who chose a false-positive rate of $5 \%$ for Down's syndrome detection. ${ }^{3}$

\section{Fetal abnormality}

Fetal abnormality included the chromosomal aberrations that were diagnosed by amniocentesis and the structural defects that were detected by fetal ultra-sonography scanning in the first and/or the second trimester of gestation.

Amniocentesis was considered as the 'gold standard' to diagnose aneuploidy. It was offered at 15-24 weeks of gestation and indicated to women who had a positive combined test $(\geq 1 / 250)$, major fetal structural anomalies on the ultrasound examination systematically in the second trimester (18-24 weeks' gestation) and/or previous history of fetal or child chromosomal malformations.

\section{Statistics}

Results were expressed as mean and standard deviation for quantitative variables; the median and range was also determined. For categorical variables, a frequency table giving number and percentage of women in each category was established.

The receiver operator characteristic (ROC) curve method and logistic regression analysis were applied to assess the association between aneuploidy and fetal NT thickness in order to find out an optimal cut-off point for diagnostic purposes. The sensitivity, specificity, positive predictive value and false-positive rate of different fetal NT cut-off point were calculated for both of aneuploidy and trisomy 21.

Results were considered to be significant at the $5 \%$ critical level $(P$-value $<0.05)$. All calculations and analysis were performed using the Stata/IC 11.1 for Windows (Stata Corp LP, Texas, USA) software package.

\section{RESULTS}

\section{Maternal characteristics}

A total of 2500 singleton pregnancies were included in the study during the one-year investigation period.

Among them, 1097 (43.9\%) were primigravidas and the majority (67.0\%) lived in an urban area (Table 1). None of the pregnancies resulted from assisted reproduction techniques, nor had an obstetrical history of fetus and/or child chromosomal abnormalities and none of the mothers were smokers.

The risk of the abnormal baby was increased 2.7 times significantly (95\% CI 1.1-6.0 and $P<0.01$ ) in the group of advanced maternal age ( $\geq 35$ years old).

\section{Fetal characteristics}

The fetal characteristics of the 2500 studied pregnancies in the first trimester of gestation are summarized in Table 2. 
The percentage of amniocentesis in this study was $2.8 \%$ (71/2500) (95\% CI 2.2-3.6\%), with 2.7\% (68/2500) (95\% CI 2.1-3.4\%) of positive serum biochemical test (above of 1/250) showing an essential indication of this invasive testing. There were no cases of chromosomal aberrations, which were diagnosed after birth. The prevalence of fetal abnormalities was $1.5 \%(38 / 2500)$

(95\% CI 1.1-2.1\%) and the incidence of abnormal karyotype amounted 1.2\% (29/2500) (95\% CI 0.8-1.7\%). In these 29 cases of aneuploidy, the most frequent chromosomal aberration was trisomy 21 (16 cases) followed by trisomy 18 (7cases), as shown in Table 3.

The fetal abnormalities, including fetal deaths, are detailed in Table 3, which also displays the distribution of gestation age, CRL and fetal NT thickness for each category. Table 3 shows that fetal NT thickness average 1.5 $\pm 0.4 \mathrm{~mm}$ in healthy fetuses and $2.7 \pm 1.0 \mathrm{~mm}$ in the abnormal group. This difference was highly significant $(P<$ $0.0001)$.

\section{Correlation between fetal NT thickness and CRL}

As seen in Table 4, the distribution of fetal NT thickness values correlated well with CRL measurement $(r=$ $0.34, P=0.001$ ) (Fig. 1), in the sense that on average fetal NT thickness increased with the $5 \mathrm{~mm}$ interval defined CRL categories. Table 4 also gives the 95th percentile of fetal NT in each CRL category, the so-called P95(CRL) thresholds levels. These NT thresholds are adjusted for CRL and increase from 2.1 to $2.7 \mathrm{~mm}$ from the first to the last CRL category.

\section{Choice of fetal NT thickness for detecting fetal aneuploidy}

We established a logistic regression for calculation of risk index and probability of fetal aneuploidy:

Logit $=\log ($ odds $)=-9.149+2.569 * \mathrm{NT}(\mathrm{mm})$.

In application of this formula, the odds $=\operatorname{Pr}($ abnormal) $/ \operatorname{Pr}$ (normal), the ratio of the risk (probability) of having an abnormal fetus and the chance of the fetus being normal. Since the coefficient of NT, namely 2.569, is positive, the odds increase with NT, in other terms: the higher NT, the greater the chances of having an abnormality (Fig. 2).

Similarly, in comparison of diagnostic value in different cut-off points of fetal NT, the point at $2.4 \mathrm{~mm}$ had the highest sensitivity and specificity for detection of fetal aberration and trisomy 21, with low false-positive rate $(<5 \%)$ in our study population (Table 5). The ROC curve was drawn based on the sensitivity and specificity of fetal NT thickness and determined the cut-off point of $2.4 \mathrm{~mm}$ as the best acceptable point with an eligible area under ROC (0.86) (Fig. 3).

\section{Comparison of fetal abnormalities detected by using different fetal NT thickness cut-off points}

Table 6 compared the number of chromosomal abnormalities detected by using the four different fetal NT thickness cut-off points. When using the fetal NT thickness cut-off point of $2.4 \mathrm{~mm}$, the detection rate of chromosomal defect and trisomy 21 was the highest (19/29 cases and 12/16 case, respectively) of the four cut-off points of fetal NT thickness.

Table 1 Demographic characteristics of study pregnancies $(n=2500)$

\begin{tabular}{|c|c|c|c|c|}
\hline & Mean \pm SD & Median & Number $(\%)$ & Range \\
\hline Maternal age (years) & $28.9 \pm 4.5$ & 28.0 & & $18-47$ \\
\hline$\geq 35$ years & & & $302(12.1)$ & \\
\hline$<35$ years & & & $2198(87.9)$ & \\
\hline Gestation & & 1.0 & & $1-5$ \\
\hline 1 & & & $1037(41.5)$ & \\
\hline 2 & & & $1260(50.4)$ & \\
\hline$\geq 3$ & & & $203(8.1)$ & \\
\hline Parity & & 1.0 & & $0-4$ \\
\hline 0 & & & $1097(43.9)$ & \\
\hline 1 & & & $1266(50.6)$ & \\
\hline 2 & & & $135(5.4)$ & \\
\hline$\geq 3$ & & & $2(0.1)$ & \\
\hline \multicolumn{5}{|l|}{ Living environment } \\
\hline Urban & & & $1676(67.04)$ & \\
\hline Suburban & & & $558(22.32)$ & \\
\hline Rural & & & $266(10.64)$ & \\
\hline
\end{tabular}


$\mathrm{SD}$, standard deviation.

Table 2 Fetal characteristic in the first trimester $(n=2500)$

\begin{tabular}{llll}
\hline & Mean \pm SD & Median & Range \\
\hline $\begin{array}{l}\text { Gestational age } \\
\text { (weeks) }\end{array}$ & $11.8 \pm 0.6$ & 12.1 & $11.0-13.6$ \\
CRL (mm) & $55.4 \pm 8.0$ & 55.0 & $45-83$ \\
BPD (mm) & $20.3 \pm 2.8$ & 20.0 & $14-27$ \\
NT (mm) & $1.6 \pm 0.5$ & 1.5 & $0.7-6.0$ \\
\hline
\end{tabular}

BPD, biparietal diameter; CRL, crown-rump length; NT, nuchal translucency; SD, standard deviation

Table 3 Characteristics of fetal abnormalities $(n=2500)$

\begin{tabular}{llllllll}
\hline & Number & CRL $(\mathrm{mm})$ & \multicolumn{2}{c}{ Gestational age (weeks) } & \multicolumn{2}{c}{ Fetal NT thickness $(\mathrm{mm})$} \\
& $(\%)$ & Mean \pm SD & Range & Mean \pm SD & Range & Mean \pm SD & Range \\
\hline Normal & $2462(98.48)$ & $55.4 \pm 8.0$ & $45-83$ & $11.9 \pm 0.8$ & $11.0-13.6$ & $1.5 \pm 0.4$ & $0.7-4.8$ \\
Abnormal & $38(1.52)$ & $56.4 \pm 6.8$ & $45-66$ & $11.9 \pm 0.5$ & $11.0-12.5$ & $2.7 \pm 1.0$ & $0.8-6.0$ \\
Fetal deaths & $9(0.36)$ & $53.9 \pm 7.3$ & $45-66$ & $11.7 \pm 0.6$ & $11.0-12.5$ & $3.0 \pm 0.3$ & $2.5-3.5$ \\
Aneuploidy & $29(1.16)$ & $57.0 \pm 6.7$ & $45-66$ & $11.6 \pm 0.0$ & $11.0-12.5$ & $2.6 \pm 1.1$ & $0.8-6.0$ \\
Trisomy 21 & $16(0.64)$ & $56.4 \pm 7.5$ & $45-66$ & $12.0 \pm 0.5$ & $11.2-12.5$ & $2.7 \pm 1.1$ & $0.8-6.0$ \\
Trisomy 18 & $7(0.28)$ & $60.7 \pm 3.1$ & $58-65$ & $12.3 \pm 0.1$ & $12.2-12.4$ & $2.7 \pm 1.0$ & $1.7-4.8$ \\
47,XXX & $2(0.08)$ & $53.0 \pm 0.0$ & $53-53$ & $11.6 \pm 0.0$ & $11.6-11.6$ & $3.1 \pm 1.3$ & $2.1-4.0$ \\
47,XXY & $4(0.16)$ & $54.8 \pm 7.9$ & $45-63$ & $11.8 \pm 0.6$ & $11.0-12.3$ & $2.1 \pm 1.4$ & $0.9-4.0$ \\
\hline
\end{tabular}

CRL, crown-rump length; NT, nuchal translucency; SD, standard deviation.

Table 4 The mean $\pm S D$ and median of fetal NT according to 5 mm interval of CRL category $(n=2500)$

\begin{tabular}{llllllllll}
\hline $\begin{array}{l}\text { CRL } \\
(\mathrm{mm})\end{array}$ & Number & \multicolumn{2}{l}{ Maternal age (years) } & CRL $(\mathrm{mm})$ & \multicolumn{2}{c}{ NT $(\mathrm{mm})$} & & \multicolumn{2}{c}{ P95 $(\mathrm{CRL})(\mathrm{mm})$} \\
& & Mean $\pm \mathrm{SD}$ & Median & Mean $\pm \mathrm{SD}$ & Median & Mean \pm SD & Median & Mean \pm SD & Median \\
\hline $45-49$ & 818 & $28.9 \pm 4.3$ & 28 & $46.9 \pm 1.9$ & 46 & $1.4 \pm 0.4$ & 1.3 & $2.10 \pm 0.04$ & 2.1 \\
$50-54$ & 530 & $28.8 \pm 4.6$ & 28 & $52.9 \pm 1.4$ & 53 & $1.5 \pm 0.4$ & 1.4 & $2.23 \pm 0.03$ & 2.2 \\
$55-59$ & 490 & $29.2 \pm 4.7$ & 28 & $57.9 \pm 1.4$ & 58 & $1.6 \pm 0.4$ & 1.6 & $2.34 \pm 0.03$ & 2.3 \\
$60-64$ & 362 & $28.7 \pm 4.3$ & 28 & $62.8 \pm 1.4$ & 63 & $1.8 \pm 0.5$ & 1.7 & $2.45 \pm 0.03$ & 2.5 \\
$65-69$ & 199 & $28.1 \pm 4.3$ & 28 & $67.6 \pm 1.5$ & 67 & $1.8 \pm 0.5$ & 1.8 & $2.56 \pm 0.03$ & 2.5 \\
$\geq 70$ & 101 & $28.9 \pm 4.1$ & 29 & $74.2 \pm 3.1$ & 73 & $1.8 \pm 0.4$ & 1.8 & $2.71 \pm 0.07$ & 2.7 \\
Total & 2500 & $28.9 \pm 4.5$ & 28 & $55.4 \pm 8.0$ & 55 & $1.6 \pm 0.5$ & 1.5 & $2.29 \pm 0.18$ & 2.5 \\
\hline
\end{tabular}

CRL, crown-rump length; NT, nuchal translucency; SD, standard deviation.

Table 5 Sensitivity, specificity, positive predictive value (PPV), and false-positive rate (FPR) in different cut-off point of fetal NT thickness for detection aneuploidy and trisomy 21

\begin{tabular}{llllll}
\hline & $\begin{array}{l}\text { NT cut-off point } \\
(\mathrm{mm})\end{array}$ & $\begin{array}{l}\text { Specificity } \\
(\%)\end{array}$ & $\begin{array}{l}\text { Sensitivity } \\
(\%)\end{array}$ & $\begin{array}{l}\text { PPV } \\
(\%)\end{array}$ & $\begin{array}{l}\text { FPR } \\
(\%)\end{array}$ \\
\hline Aneuploidy & $\geq 2.4$ & 95.7 & 65.5 & 15.2 & 4.3 \\
& $\geq 2.5$ & 97.2 & 55.2 & 19.1 & 2.8 \\
& $\geq 3.0$ & 99.4 & 17.2 & 25.0 & 0.6 \\
Trisomy 21 & $\geq$ P95 (CRL) & 95.9 & 58.6 & 14.4 & 4.1 \\
& $\geq 2.4$ & 95.1 & 75.0 & 9.0 & 4.9 \\
& $\geq 2.5$ & 96.7 & 65.8 & 12.0 & 3.3 \\
& $\geq 3.0$ & 99.1 & 12.5 & 8.33 & 0.9 \\
& $\geq$ P95 (CRL) & 95.4 & 68.8 & 8.37 & 4.6 \\
\hline
\end{tabular}

CRL, crown-rump length; NT, nuchal translucency. 
Table 6 Fetal chromosomal abnormalities at the different cut-off point of fetal NT thickness $(n=2500)$

\begin{tabular}{llllll}
\hline & Number & \multicolumn{4}{c}{ Cut-off point of fetal NT thickness } \\
& & $\geq 2.4 \mathrm{~mm}$ & $\geq 2.5 \mathrm{~mm}$ & $\geq 3.0 \mathrm{~mm}$ & $\geq$ P95 (CRL) \\
\hline Normal & 2462 & 107 & 70 & 19 & 104 \\
Fetal demised & 9 & 7 & 6 & 0 & 5 \\
Aneuploidy & 29 & 19 & 16 & 5 & 17 \\
Trisomy 21 & 16 & 12 & 11 & 2 & 11 \\
Trisomy 18 & 7 & 4 & 3 & 1 & 4 \\
47XXX & 2 & 1 & 1 & 1 & 1 \\
47XXY & 4 & 2 & 1 & 1 & 1 \\
Total & 2500 & 133 & 92 & 24 & 126 \\
\hline
\end{tabular}

CRL, crown-rump length; NT, nuchal translucency.

Figure 1 The distribution of fetal nuchal translucency (NT) thickness in corresponding to crown-rump length measurement. CI, confidence interval.

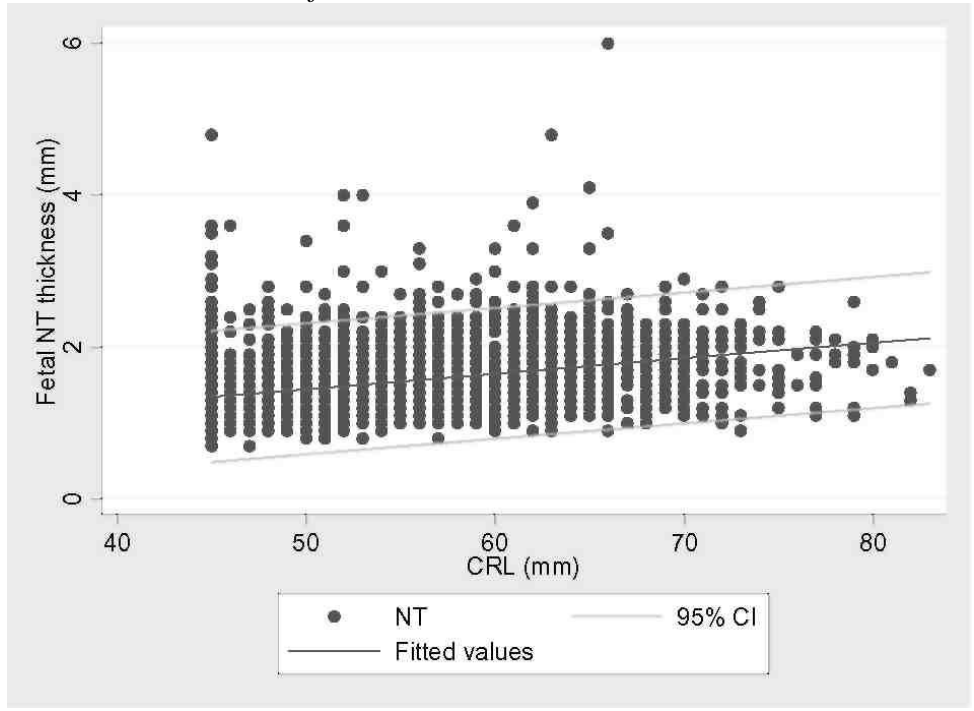

Figure 2 Probability of fetal abnormality following to fetal nuchal translucency (NT) thickness value.

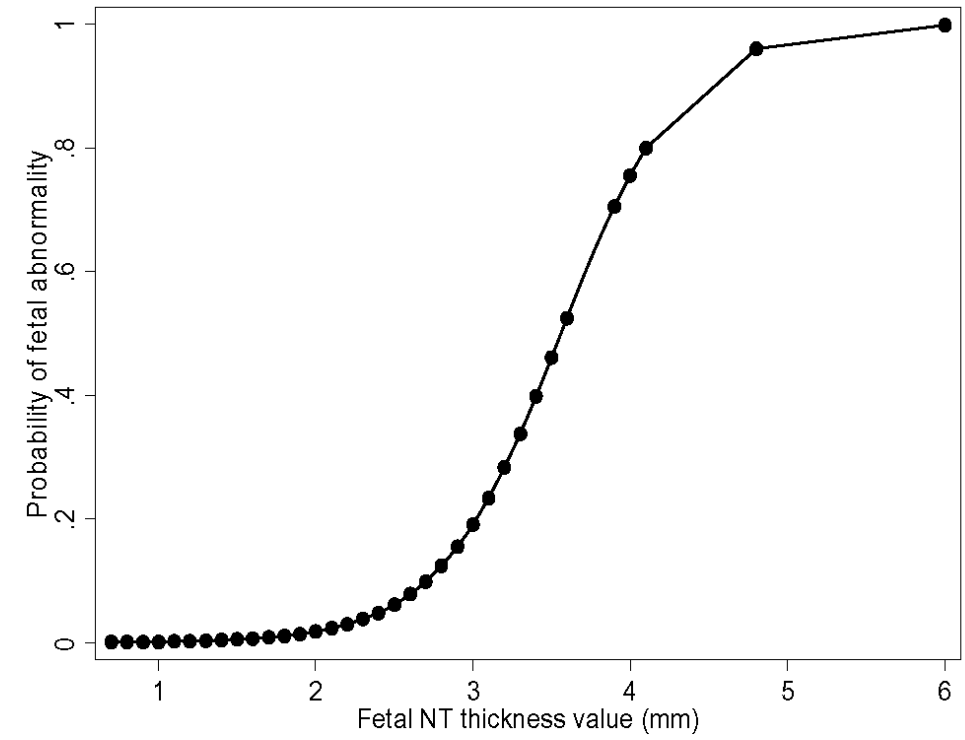


Figure 3 The receiver operator characteristic (ROC) curve of the fetal nuchal translucency (NT) thickness of sensitivity and specificity for screening fetal abnormalities.

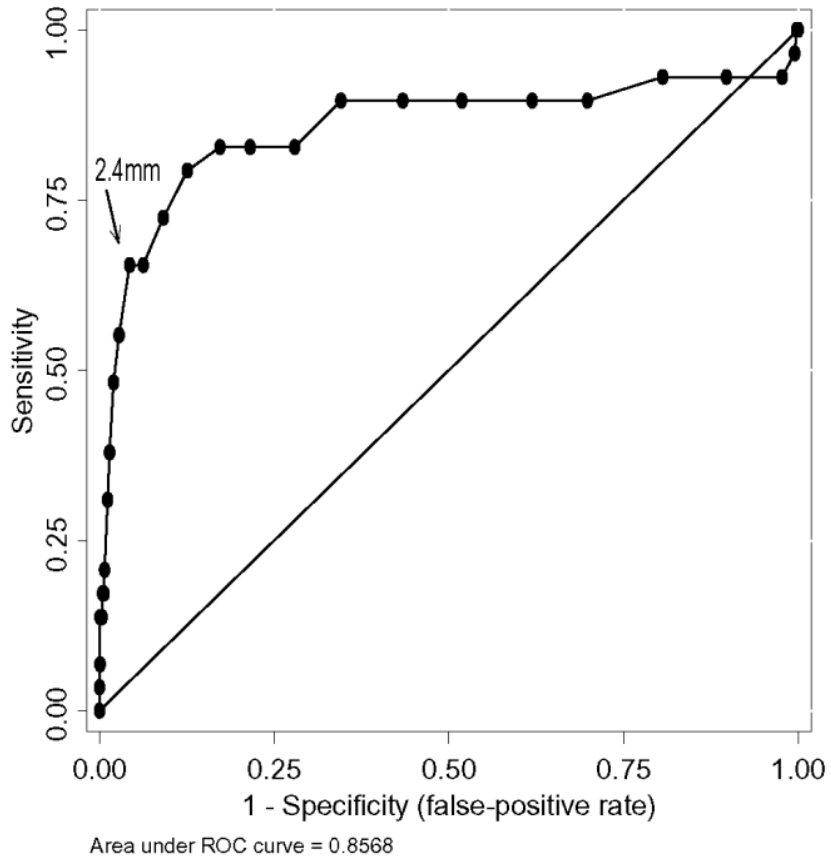

\section{DISCUSSION}

This study showed that measurement of fetal NT thickness for screening chromosomal abnormalities can be potentially effective in the Vietnamese population. Using a cut-off point of $2.4 \mathrm{~mm}$, the detection rate for aneuploidy was 65.5 with $4.3 \%$ of false-positive rate.

The mean age of women in this study was $28.9 \pm 4.5$ years, a figure similar to that of Adekunle et al. (28.8 years $)^{19}$ and Souka et al. (29 years) ${ }^{16}$ who studied fetal abnormalities (included trisomy 21 ) in a population of low-risk pregnancies. Because $58 \%$ of babies with Down's syndrome were born to women aged $\geq 35$ years, ${ }^{20}$ advanced maternal age is one of the criterion defining a high-risk pregnancy. In our study, only $12.1 \%$ of women were in this category, hence reducing the influence of advanced maternal age on the incidence of this fetal abnormality. Moreover, most abnormalities (approximately 70\%) occurred in the Tow-risk' group as in other studies, ${ }^{2,21}$ thus our results can be seen as representative of the Vietnamese population.

An increasing relationship was highlighted between fetal NT thickness and gestation age (or CRL) as in previously published studies. ${ }^{12,22-24}$ The mean of NT thickness was $1.6 \pm 0.5 \mathrm{~mm}$, quite comparable to the values $1.56 \pm 0.41 \mathrm{~mm}$ by Hsu et al. in Taiwan, ${ }^{12} 1.62 \pm 0.5 \mathrm{~mm}$ by Chung et al. in South Korea ${ }^{22}$ but was lower than results of Abele et al. $(1.9 \mathrm{~mm})$ in Germany ${ }^{25}$ and Acacio et al. $(2.18 \mathrm{~mm})$ in Brazil. ${ }^{14}$ In fact, there were no clinical relevant effects in NT measurements by ethnic origin following Adekunle et al., and Chen et al. ${ }^{19,26}$ Fetal NT thickness (in particular median and 95th percentile) adjusted for CRL measurement were not different from those found in the studies of Hsu et al. and Chung et al. ${ }^{12,22}$ Recently, Salomon et al. published reference charts and equations for fetal NT in a French population, based on a large sample of 19198 fetal NT measurements. They found that the median of fetal NT thickness were comparable to those studied in other populations and the 99th percentile was the same value as that reported by the FMF guidelines (around $3 \mathrm{~mm}$ ). ${ }^{18,24}$ Abele et al. measured fetal NT thickness in a sample of fetuses with a larger CRL mean than our study: $63.3 \mathrm{~mm}$ (range 45.0-84.0 mm) versus $55.4 \mathrm{~mm}$ (range 45.0-83.0 mm), ${ }^{25}$ whereas, Acacio et al. investigated fetal NT thickness in high-risk group women (whose average age were 35.8 years). ${ }^{14}$ Chorionic villus sampling is not done in our clinic, thus the amniocentesis was used as our 'gold standard' of diagnostic test for fetal aneuploidy (positive or negative) and to assess the efficacy of fetal NT thickness at the different cut-off points. Seventy-one (2.8\%) women gave their consent to perform an amniocentesis. In fact, the rate of amniocentesis was influenced by the choice of different cut-off points for positive screening algorithms $(1 / 200,1 / 237,1 / 307 \ldots$ of the combined test, integrated test, sequential screening, contingent screening, or triple test ... ). ${ }^{27}$ Based on each screening strategy and the risk of obstetrical population, the amniocentesis rate varied from $11 \%$ in France ${ }^{28}$ and $16 \%$ in the Parisian and Yveline's population, ${ }^{21,29}$ to $84.3 \%$ in China ${ }^{30} \mathrm{We}$ found $1.2 \%$ of fetal aneuploidy in our study. This prevalence of chromosomal aberration was similar to $1.2 \%$ by Chung et al. ${ }^{22}$ in South Korea and $1.91 \%$ by Zhang et al.'s report ${ }^{30}$ in China. However, our findings were higher than those studied by Romosan et al. in a 
Swedish population $(0.31 \%)^{31}$ and lower than those of Nicolaides et al. $(3 \%)$, who chose a high-risk population (827 women of advanced maternal age, or family with history chromosomal abnormalities). ${ }^{32}$

Since fetal NT thickness increases as CRL increases, it would seem necessary to account for this relation in predicting fetal chromosomal abnormalities, especially trisomy 21 from NT measurements. ${ }^{2,12,22,23,33}$ In the literature, many studies have recommended fetal NT thickness cut-off points such as $3.0 \mathrm{~mm}, 2.5 \mathrm{~mm}, 95 \mathrm{th}$ percentile or 99th percentile of distribution. The choice of suitable cut-off point depended on the sensitivity, specificity, positive predictive value and false-positive rate of the test in study population. ${ }^{34}$ Nicolaides et al. showed that fetal NT thickness $\geq 3.0 \mathrm{~mm}$ was an useful first trimester marker for fetal chromosomal abnormalities. ${ }^{32}$ Roberts et al. reported that if a NT cut-off $\geq 3 \mathrm{~mm}$ is used, $6 \%$ of unselected fetuses between 8 and 13 weeks of gestation are classified as abnormal. ${ }^{35}$ The sensitivity of the cut-off at $3.0 \mathrm{~mm}$ for detecting trisomy 21 was reported to be $75 \%$ by Audibert et al. ${ }^{13}$ Recently, Alexioy et al. preferred to fix the cut-off point of fetal NT thickness at $2.5 \mathrm{~mm}$ for the detection of fetal chromosomal defects with a the positive predictive value of $14.8 \% .^{15}$ Acacio et al. also found 69.5 and $75 \%$ sensitivity for aneuploidy and for trisomy 21 , alternatively, at the same threshold of $2.5 \mathrm{~mm} .{ }^{14}$ To confirm the increase of fetal NT according to gestational age as stated by Snijder, ${ }^{33}$ Hsu et al. concluded that it was not appropriate to use a fixed cut-off point for NT thickness regardless of the gestational age in NT screening for Down's syndrome. They proposed when determining a given increase in NT thickness, it is essential to take the gestation age or CRL in to account. ${ }^{12}$ In addition, the sensitivity and the false-positive rate for total chromosomal aberrations by using of the P95 CRLdependent cut-off were 70.9 and 5.8\%, respectively, as reported by Kim et al. ${ }^{17}$

In many reports, the use of a cut-off point of $2.5 \mathrm{~mm}$ had been accepted with a the false-positive rate $5.5 \%$ in Scott et al., ${ }^{36} 5.7 \%$ in Pandya et al. ${ }^{37}$ and $6.3 \%$ in Jou et $a l .{ }^{38}$ In our study, at $2.5 \mathrm{~mm}$, we found a lower falsepositive rate $(2.8 \%)$ than these authors and a higher positive predictive value $(19.1 \%)$ than Alexioy et al. $(14.8 \%) .{ }^{15}$ However, its sensitivity dropped abruptly by $10 \%$ in comparison to a cut-off at $2.4 \mathrm{~mm}$ (55.2 vs $65.5 \%$ ). Our study purpose was to assess the most suitable fetal NT cut-off point when screening for fetal chromosomal abnormalities (including trisomy 21) in pregnant Vietnamese women. It is clearly appropriate to select the fetal NT thickness cut-off point with the highest sensitivity and a false-positive rate (1 - specificity) less than 5\%. By ROC curve analysis, we found that the cut-off point at $2.4 \mathrm{~mm}$ satisfied these conditions: $65.5 \%$ sensitivity, $15.2 \%$ positive predictive value and $4.3 \%$ false positive. In addition, at $2.4 \mathrm{~mm}$ cut-off point, we increased the detection of number of chromosomal aberrations $(14.3 \%, 19 / 133)$ and of trisomy $21(12.8 \%$, $12 / 133)$. These results paralleled those of $14.8 \%$ of aneuploidy (18/122) and 9\% of trisomy $21(11 / 122)$ obtained by Alexioy et al., who selected $2.5 \mathrm{~mm}$ as the fixed cut-off point of increased fetal NT thickness. ${ }^{15}$ The study of Alexioy et al. reinforces our choice of $2.4 \mathrm{~mm}$ as the best fixed cut-off of increased fetal NT thickness for screening chromosomal abnormalities and trisomy 21 . When using logistic regression analysis, a cut-off at 2.4 $\mathrm{mm}$ corresponded to a probability of abnormal fetus of $5 \%$, and probability of $95 \%$ normal fetus. The use of a fetal NT cut-off point at $2.4 \mathrm{~mm}$ has not been mentioned before in literature.

With specific regards to trisomy 21 screening, we found $75 \%$ sensitivity and $95.13 \%$ specificity by using the NT thickness cut-off point at $2.4 \mathrm{~mm}$. The sensitivity results was similar to that obtained by Pandya et al. in the United Kingdom, ${ }^{37}$ by Audibert $\mathrm{F}$ et al. in France, ${ }^{13}$ by Kim et al. ${ }^{22}$ in South Korea and by Acacio et al. in Brazil. ${ }^{14}$ With cut-off point of $2.4 \mathrm{~mm}$, we also found that the rate of trisomy 21 was three times higher than trisomy 18 (12/16 cases of trisomy 21 vs 4/7 cases of trisomy 18) as reported by Acacio et al. ${ }^{14}$

Recently, Fink et al. indicated that fetal NT thickness of $2 \mathrm{~mm}$ or more posed a significant risk for adverse perinatal outcome (adjusted OR 14.3; 95\% CI 1.8-35; $P<0.001){ }^{39}$ This showed that the fetal NT cut-off point can vary greatly from 2 to $10 \mathrm{~mm}$, depending on the chromosomal defect to be detected; with rates varying from 11 to $88 \%{ }^{2}$

We conclude that an increased fetal NT of $2.4 \mathrm{~mm}$ corresponded to a suitable cut-off point for use in the existing screening program for detection of fetal abnormalities (especially trisomy 21) in the south of Vietnam. Since this is the first study into prediction of aneuploidy in Vietnam using fetal NT thickness, the fixed NT cut-off point at $2.4 \mathrm{~mm}$ will be implemented routinely and assessed in other obstetric populations.

\section{Acknowledgments}

This study was funded by Belgium Technical Cooperation (BTC). The authors wish to thank Professor Adelin Albert, Department of Public Health in the University of Liège, Belgium, for his statistical help in analyzing the data and Dr Sarah Hoskins for her revisions in presenting this manuscript. 
Published in : Journal of Obstetrics and Gynaecology Research (2010)

Status : Postprint (Author's version)

\section{REFERENCES}

1. McAuliffe FM, Fong KW, Toi A, Chitayat D, Keating S, Johnson JA. Ultrasound detection of fetal anomalies in conjunction with firsttrimester nuchal translucency screening: A feasibility study. Am J Obstet Gynecol 2005; 193: 1260-1265.

2. Nicolaides KH. Screening for chromosomal defects. Ultrasound Obstet Gynecol 2003; 21: 313-321.

3. Wald NJ, Cuckle HS, Densem JW et al. Maternal serum screening for Down's syndrome in early pregnancy. BMJ 1988; 297: 883-887.

4. Wald NJ, Hackshaw AK. Combining ultrasound and biochemistry in first trimester screening for Down, s syndrome. Prenat Diagn 1997; 17: $821-829$.

5. Wald NJ, Watt HC, Hackshaw AK. Integrated screening for Down's syndrome on the basis of tests performed during the first and second trimesters. N Engl J Med 1999; 341: 461-467

6. Nicolaides KH. First-trimester screening for chromosomal abnormalities. Semin Perinatol 2005; 29: 190-194.

7. Leung TY, Chan LW, Law LW et al. First trimester combined screening for Trisomy 21 in Hong Kong: Outcome of the first 10000 cases, J Matern Fetal Neonatal Med 2009; 22: 300-304.

8. Theodoropoulos P, Lolis D, Papageorgiou C, Papaioannou S, Plachouras N, Makrydimas G. Evaluation of first-trimester screening by fetal nuchal translucency and maternal age. Prenat Diagn 1998; 18: 133-137.

9. Marsis IO. Screening for Down syndrome using nuchal translucency thickness and nasal bone examination at advanced maternal age in Jakarta: A preliminary report, J Med Ultrasound 2004; 12: 1-6.

10. Brady AF, Pandya PP, Yuksel B, Greenough A, Patton MA, Nicolaides KH. Outcome of chromosomally normal live births with increased fetal nuchal translucency at 10-14 weeks' gestation, J Med Genet 1998; 35: 222-224.

11. Chitty LS, Kagan KO, Molina FS, Waters JJ, Nicolaides KH. Fetal nuchal translucency scan and early prenatal diagnosis of chromosomal abnormalities by rapid aneuploidy screening: Observational study. BMJ 2006; 332: $452-455$.

12. Hsu JJ, Hsieh CC, Chiang $\mathrm{CH}$ et al. Preliminary normal reference values of nuchal translucency thickness in Taiwanese fetuses at $11-14$ weeks of gestation. Chang Gung Med J 2003; 26: 12-19.

13. Audibert F, Dommergues M, Benattar C, Taieb J, Champagne C, Frydman R. Diagnosis of trisomy 21: Nuchal translucency and/or serum markers? [French]. Gynecol Obstet Fertil 2001; 29: 599-604.

14. Acacio GL, Barini R, Pinto Junior W, Ximenes RL, Pettersen H, Faria M. Nuchal translucency: An ultrasound marker for fetal chromosomal abnormalities. Sao Paulo Med J 2001; 119: 19-23.

15. Alexioy E, Alexioy E, Trakakis E et al. Predictive value of increased nuchal translucency as a screening test for the detection of fetal chromosomal abnormalities, J Matern Fetal Neonatal Med 2009; 22: 857-862.

16. Souka AP, Pilalis A, Kavalakis I et al. Screening for major structural abnormalities at the 1l-tol4-week ultrasound scan. Am J Obstet Gynecol 2006; 194: 393-396.

17. Kim MH, Park SH, Cho HJ et al. Threshold of nuchal translucency for the detection of chromosomal aberration: Comparison of different cut-offs, J Korean Med Sci 2006; 21: 11-14.

18. Nicolaides KH, Sebire NJ. The 11-14-Week Scan -Diploma in Fetal Medicine \& ISUOG Educational Series. 2001, ISUOG Educational Committee.

19. Adekunle O, Gopee A, el-Sayad M, Thilaganathan B. Increased first trimester nuchal translucency: Pregnancy and infant outcomes after routine screening for Down's syndrome in an unselected antenatal population. Br J Radiol 1999; 72: 457-460.

20. Wellesley D, Boyle T, Barber J, Howe DT. Retrospective audit of different antenatal screening policies for Down's syndrome in eight district general hospitals in one health region. BMJ 2002; 325: 15.

21. Bussieres L, Rozenberg P, Bault JP, ViUe Y; Echo PAPP-A 78 Study. First trimester Down syndrome screening program using nuchal translucency and maternal serum markers: The Echo PAPP-A.78 study [French], J Gynecol Obstet Biol Reprod (Paris) $2004 ; 33$ (1 Suppl): S61-S66.

22. Chung JH, Yang JH, Song MJ et al. The distribution of fetal nuchal translucency thickness in normal Korean fetuses, J Korean Med Sci 2004; 19: 32-36.

23. Hyett J, Perdu M, Sharland G, Snijders R, Nicolaides KH. Using fetal nuchal translucency to screen for major congenital cardiac defects at 10-14 weeks of gestation: Population based cohort study. BMJ 1999; 318: 81-85.

24. Salomon LJ, Chalouhi GE, Bernard JP, Ville Y. Épaisseur de la clarté nucale A 11. 14 SA: Courbes et équations françaises. Journal Gynécologie Obstétrique Biologie la Reproduction 2009; 38: 635-641.

25. Abele H, Wagner N, Hoopmann M, Grischke EM, Wallweiner D, Kagan KO. Effect of deviation away from the mid-sagittal plane in the measurement of fetal NT. Ultrasound Obstet Gynecol 2010; 35: 525-529.

26. Chen M, Lam YH, Tang MH. The effect of ethnic origin on nuchal translucency at 10.14 weeks of gestation. Prenat Diagn 2002; 22: $576-578$

27. Gekas J, Gagne G, Bujold E et al. Comparison of different strategies in prenatal screening for Down's syndrome: Cost effectiveness analysis of computer simulation. BMJ 2009; 338 (feb13_1): b138.

28. Blonde B, Norton J. Trends in main indicators of perinatal health in France between 1995 and 1998. Results from the National Perinatal Surveys. J Gynecol Obstet Biol Reprod (Paris) 2001; 30: 552-564

29. De Vigan C, Vodovar V, Goujard J. Mothers' knowledge of screening for trisomy 21 in 1999: A survey in Paris maternity units. Fur J 
Published in : Journal of Obstetrics and Gynaecology Research (2010)

Status : Postprint (Author's version)

Obstet Gynecol Reprod Biol 2002; 104: 14-20.

30. Zhang L, Zhang XH, Liang MY, Ren MH. Prenatal cytoge-netic diagnosis study of 2782 cases of high-risk pregnant women. Chin Med $J$ (Engl) 2010; 123: 423430.

31. Romosan G, Henriksson E, Rylander A, Valentin L. Diagnostic performance of routine ultrasound screening for fetal abnormalities in an unselected Swedish population in 2000-2005. Ultrasound Obstet Gynecol 2009; 34: 526-533.

32. Nicolaides KH, Azar G, Byrne D, Mansur C, Marks K. Fetal nuchal translucency: Ultrasound screening for chromosomal defects in first trimester of pregnancy. BMJ 1992; 304: 867-869.

33. Snijders RJ, Noble P, Sebire N, Souka A, Nicolaides KH. UK multicentre project on assessment of risk of trisomy 21 by maternal age and fetal nuchal translucency thickness at 10-14 weeks of gestation. Fancet 1998; 351: 343-346.

34. Hyett J, Nicolaides KH. Prenatal Diagnosis, Chapter 24. New York, United States: Mc Graw-Hill. Medical publishing division, 2006.

35. Roberts LJ, Bewley S, Mackinson AM, Rodeck CH. First trimester fetal nuchal translucency: Problems with screening the general population. 1. Br J Obstet Gynaecol 1995; 102: 381-385.

36. Scott F, Boogert A, Sinosich M, Anderson J. Establishment and application of a normal range for nuchal translucency across the first trimester. Prenat Diagn Interv Radiol 1996; 16: 629-634.

37. Pandya PP, Snijders RJ, Johnson SP, De Lourdes Brizot M, Nicolaides KH. Screening for fetal trisomies by maternal age and fetal nuchal translucency thickness at 10 to 14 weeks of gestation. Br J Obstet Gynaecol 1995; 102: 957-962.

38. Jou HJ, Wu SC, Li TC, Hsu HC, Tzeng CY, Hsieh FJ. Relationship between fetal nuchal translucency and crown-rump length in an Asian population. Ultrasound Obstet Gynecol 2001; 17: 111-114.

39. Fink M, Sheiner E, Hershkovitz R et al. Nuchal translucency thickness in euploid fetuses: Is two millimeters too risky? Am J Perinatol 2009; 26: 303-307. 